\title{
Aluminum- and Vanadium-free Titanium Alloys for Medical Applications
}

\author{
Fabian Haase* ${ }^{1}$, Carsten Siemers ${ }^{1}$, Lina Klinge ${ }^{1}$, Cheng Lu ${ }^{1}$, Patric Lang ${ }^{1}$, Stephan Lederer, ${ }^{2}$ Till König $^{3}$,
} Joachim Rösler ${ }^{1}$

${ }^{1}$ Technische Universität Braunschweig, Institute for Materials, Langer Kamp 8, 38106 Braunschweig, Germany

${ }^{2}$ DECHEMA-Forschungsinstitut, Corrosion, Theodor-Heuss-Allee 25, 60486 Frankfurt am Main, Germany

${ }^{3}$ DECHEMA-Forschungsinstitut, High Temperature Materials, Theodor-Heuss-Allee 25, 60486 Frankfurt am Main, Germany

*F.Haase@tu-braunschweig.de

\begin{abstract}
$\underline{\text { Abstract }}$
CP-Ti, Ti 6Al 4V (ELI), and Ti 6Al 7Nb are often used for manufacturing osteosynthesis products or implants. However, researches have revealed that $\mathrm{Al}$ and $\mathrm{V}$ can have detrimental effects on the human body. Therefore, several Al- and V-free near- $\alpha$ and $(\alpha+\beta)$ titanium alloys have been developed on the basis of CP-Ti Grade $4^{+}$(Ti $0.4 \mathrm{O} 0.5 \mathrm{Fe} 0.08 \mathrm{C}$ ). They should possess similar or better mechanical properties than Ti 6Al 4V (ELI) combined with an improved biocompatibility and good corrosion resistance. $\mathrm{O}, \mathrm{C}, \mathrm{Fe}, \mathrm{Au}, \mathrm{Si}, \mathrm{Nb}$, or Mo have been used as alloying elements, which are either already present in the human body or are biocompatible. Several of the studied alloys show a strength and ductility fulfilling the requirements of Ti 6Al 4V ELI as specified in ASTM F136. For instance, Ti 0.44O 0.5Fe 0.08C 2.0Mo exhibits a YTS of approx. 1005 $\mathrm{MPa}$, an UTS of approx. $1015 \mathrm{MPa}$, and an elongation at rupture of at least $17 \%$. Therefore, one or more of the studied alloys are promising candidates for replacing Ti 6Al 4V ELI in osteosynthesis and implant applications.
\end{abstract}

\section{Introduction}

Titanium alloys combine good mechanical properties with biocompatibility and corrosion resistance and are, therefore, very well suited for medical applications [1-3]. For instance, CP-Ti and Ti 6Al 4V are often used for manufacturing implants [2]. Since $\mathrm{V}$ is toxic and can adversely affect the human body [2-4], Ti 6Al 7Nb was designed on the basis of Ti 6Al 4V to tackle possible negative health effects of this alloying element $[1,5]$. Al is also a known toxic element $[3,4]$ and might cause Alzheimer's disease [2]. Additionally, Mandriota et al. [6] found out experimentally in mouse cancer models that aluminum chloride can cause breast cancer. Consequently, the high Al content of Ti $6 \mathrm{Al} 4 \mathrm{~V}$ (ELI) and of Ti $6 \mathrm{Al} 7 \mathrm{Nb}$ is (still) of concern and long term negative health effects cannot be excluded per se.

Therefore, in the present study, several Al- and V-free titanium alloys for osteosynthesis and implant applications have been developed. They are all based on CP-Ti Grade $4^{+}$(CP-Ti Grade 4 with maximum allowed contents of O, Fe, and $\mathrm{C}$ according to ASTM F67 - Ti $0.4 \mathrm{O} 0.5 \mathrm{Fe} 0.08 \mathrm{C}$ ), which was already discussed in [7], and contain $\mathrm{Mo}, \mathrm{Au}, \mathrm{Si}$ or $\mathrm{Nb}$ as additional solid solution strengthener. $\mathrm{O}, \mathrm{C}, \mathrm{Fe}$, and $\mathrm{Mo}$ are essential for the human body [8], whereas $\mathrm{Au}, \mathrm{Si}$, and $\mathrm{Nb}$ are biocompatible [3]. Table 1 lists the chemical composition of some of the studied alloys which are discussed in this paper. Corrosion experiments show that they (Ti $0.44 \mathrm{O} 0.08 \mathrm{C} 0.5 \mathrm{Fe} 0.4 \mathrm{Si} 0.1 \mathrm{Au}$ not yet tested) possess a better corrosion resistance than Ti $6 \mathrm{Al} 4 \mathrm{~V}$ ELI. Due to the exclusion of potential critical elements, it is suspected that these alloys show a better biocompatibility than Ti 6Al 4V (ELI) combined with similar or better mechanical properties.

Table 1: Chemical composition of the studied alloys (differences between the alloys are printed in bold)

\begin{tabular}{|c|c|}
\hline Ti $0.42 \mathrm{O} 0.08 \mathrm{C} 0.5 \mathrm{Fe} 0.4 \mathrm{Si}$ & Ti $\mathbf{0 . 4 4 0} 0.08 \mathrm{C} 0.5 \mathrm{Fe} \mathbf{0 . 4 S i}$ \\
\hline Ti 0.400 0.08C 0.5Fe 2.0Mo & Ti $\mathbf{0 . 4 4 0} 0.08 \mathrm{C} 0.5 \mathrm{Fe}$ 2.0Mo \\
\hline $\mathrm{Ti} 0.40 \mathrm{O} 0.08 \mathrm{C} 0.5 \mathrm{Fe} 2.0 \mathrm{Nb}$ & Ti $\mathbf{0 . 4 4 0} 0.08 \mathrm{C} 0.5 \mathrm{Fe} 2 . \mathbf{0 N b}$ \\
\hline $\mathrm{Ti} \mathbf{0 . 4 0 O} 0.08 \mathrm{C} 0.5 \mathrm{Fe}$ 0.3Si $\mathbf{0 . 1 A u}$ & Ti 0.440 0.08C $0.5 \mathrm{Fe}$ 0.4Si $0.1 \mathrm{Au}$ \\
\hline
\end{tabular}

\section{Methods}

Alloy and specimen production

Laboratory-size specimens have been produced by plasma beam cold hearth melting. CP-Ti Grade 4, CP-Ti Grade 1S foil, graphite powder, $\mathrm{TiO}_{2}$ powder, gold, iron, niobium, molybdenum, and silicon chips were weighed out according to the required chemical composition. For the melting process, the chamber was evacuated and filled with Argon up to a pressure 
of $600 \mathrm{mbar}$. After three times remelting, the ingot was poured into round copper molds to cast bars (13.2 $\mathrm{mm} \mathrm{x}$ approx. 80 $\mathrm{mm}$ ) for subsequent rotary swaging. In order to release residual stresses, the resulting bars have been stress relief annealed in argon atmosphere at $700^{\circ} \mathrm{C}$ for $90 \mathrm{~min}$ followed by furnace cooling.

To achieve a recrystallized, globular microstructure the cast and annealed bars were rotary swaged in four steps to a final diameter of $10 \mathrm{~mm}$ with a diameter reduction of $0.2 \mathrm{~mm}$ in the first and $1 \mathrm{~mm}$ in each of the last three steps. Prior to deformation, the bars were heated in a standard air tube furnace at $930^{\circ} \mathrm{C}$ for $22 \mathrm{~min}$. Between each step, they were reheated at the same temperature for $5 \mathrm{~min}$. After the final pass, the bars were straightened and air cooled and finally recrystallization annealed at $705^{\circ} \mathrm{C}$ for $120 \mathrm{~min}$ followed by air cooling.

In order to compare the mechanical properties of the alloys with CP-Ti Grade 4, Ti $6 \mathrm{Al} 4 \mathrm{~V}$ ELI, and Ti $0.4 \mathrm{O} 0.5 \mathrm{Fe} 0.08 \mathrm{C}$, the latter have been produced in a very similar way, described in [9].

Two alloys (Ti $0.4 \mathrm{O} 0.5 \mathrm{Fe} 0.08 \mathrm{C} 0.3 \mathrm{Si} 0.1 \mathrm{Au}$ and $\mathrm{Ti} 0.44 \mathrm{O} 0.5 \mathrm{Fe} 0.08 \mathrm{C} 0.4 \mathrm{Si} 0.1 \mathrm{Au}$ ) were produced in larger quantities at Access in Aachen, Germany (the former alloy, approx. $6 \mathrm{~kg}$ ) and VACUCAST in Berlin, Germany (the latter alloy, approx. $22 \mathrm{~kg}$ ) via cold crucible induction melting followed by vacuum casting. The conical bars which have been cast by Access had a minimum diameter of $40 \mathrm{~mm}$ and a length of approx. $400 \mathrm{~mm}$. Some of them were first rotary swaged at TU Darmstadt in Darmstadt, Germany, to a diameter of $25 \mathrm{~mm}$ in one step, sectioned into four parts, and finally rotary swaged to a diameter of approx. $15 \mathrm{~mm}$ at Bremen University in Bremen, Germany, in one step. Prior to each deformation process, they had been annealed at $950^{\circ} \mathrm{C}$ for $60 \mathrm{~min}$. Recrystallization annealing had been done at $800^{\circ} \mathrm{C}$ for 60 min with subsequent air cooling.

The bars which have been cast by VACUCAST had a diameter of approx. $38 \mathrm{~mm}$ and a length of approx. $360 \mathrm{~mm}$. After further processing by VACUCAST, a section of one bar has been annealed at $950^{\circ} \mathrm{C}$ for $49 \mathrm{~min}$ and subsequently rolled to a thickness of approx. $8.2 \mathrm{~mm}$ in 16 steps followed by air cooling. Between each pass, the section had been annealed at $950^{\circ} \mathrm{C}$ for $10 \mathrm{~min}$. After this first deformation process, a two-stage annealing treatment $\left(1025^{\circ} \mathrm{C} / 10 \mathrm{~min} /\right.$ water quenching + $900^{\circ} \mathrm{C} / 1.5 \mathrm{~h} /$ air cooling) with the first step above $\beta$-transus has been done in order to achieve a fine $(\alpha+\beta)$-microstructure of the plate through a complete decomposition of martensite. Afterwards, the plate has been rolled to a final thickness of approx. $3.9 \mathrm{~mm}$ in several steps with a thickness reduction of approx. $0.2 \mathrm{~mm}$ during each pass. Prior to deformation, the plate has been annealed at approx. $300^{\circ} \mathrm{C}$ for $20 \mathrm{~min}$ and reheated at the same temperature for $4 \mathrm{~min}$ after each pass. After the last step, the plate has been water quenched to prevent recovery. The final recrystallization heat treatment has been done at $800^{\circ} \mathrm{C}$ with a holding time between $15 \mathrm{~min}$ and $2 \mathrm{~h}$ followed by air cooling to study the recrystallization behavior.

\section{Microstructure Investigations and phase determination}

The microstructure of the alloys has been analyzed in cross section or along the longitudinal axis. To do so, small specimens were cut, warm embedded into EpoMet ${ }^{\circledR}$ and Bakelit compound, and subsequently ground, polished, and etched. Microstructure investigations have been performed using optical and scanning electron microscopes. Additionally, element partitioning has been studied through energy dispersive x-ray spectroscopy (EDS). Phase analysis has been done by means of x-ray diffraction in Bragg-Brentano-setup or in parallel beam geometry (the latter with primary monochromator). The resulting diffraction pattern has been analyzed with CMPR [10] software and PDF2 database (release 2005).

\section{Mechanical testing}

The hardness of the embedded and polished specimens was determined through automated Vickers hardness tests (HV 10, 5 indentations). Additionally, tensile tests compliant with DIN EN ISO 6892-1, procedure B, have been carried out at room temperature with two round tensile specimens (DIN 50125 - B 5 x 25) for each alloy and subsequent assessment of the fracture surface. Furthermore, stress-controlled fatigue tests have been carried out at $\mathrm{Ti} 0.4 \mathrm{O} 0.5 \mathrm{Fe} 0.08 \mathrm{C} 0.3 \mathrm{Si} 0.1 \mathrm{Au}$ (produced in larger quantities). The specimens were hourglass-shaped according to ASTM E 466, had a metric fine thread of diameter $9 \mathrm{~mm}$, and were ground with P2500 SiC paper in axial and transverse directions after machining to remove scratches. The tests had been carried out under a frequency of $8 \mathrm{~Hz}$, an R value of approx. 0.01, and were stopped after $5 \times 10^{6}$ cycles in case no failure occurred.

\section{Results and discussion}

\section{Microstructure and phase determination}

In the as-cast and stress-relief annealed state all alloys exhibit a lamellar $(\alpha+\beta)$ microstructure. After rotary swaging and recrystallization, the microstructure of the $\mathrm{Si}$ - and $\mathrm{Nb}$-containing alloys mainly consists of lamellae, see Figure 1 , left, which exemplarily shows the microstructure of $\mathrm{Ti} 0.42 \mathrm{O} 0.08 \mathrm{C} 0.5 \mathrm{Fe} 0.4 \mathrm{Si}$. However, several grain boundaries in the lamellar structures or $\alpha_{\mathrm{p}}$-grains between the lamellae indicate that recrystallization occurred. The Si-containing alloys already exhibit a significant amount of $\beta$-phase. The corresponding grains have a size of several hundred nanometers up to a few micrometers. Local EDS measurements show that $\mathrm{Fe}$ is partly enriched along $\alpha$-lamellae grain boundaries, which is matching to the fact that $\mathrm{Fe}$ is a $\beta$-stabilizer and tends to enrich in the $\beta$-Phase due to element partitioning [1]. In terms of the 
$\mathrm{Nb}$ and Mo containing alloys, EDS analysis shows an enrichment of $\mathrm{Nb}$ and $\mathrm{Mo}$ in $\beta$-grains. Both Mo-containing alloys exhibited a significant higher degree of broken laths and more $\alpha_{\mathrm{p}}$-grains, see Figure 1, right, which exemplarily shows the microstructure of $\mathrm{Ti} 0.44 \mathrm{O} 0.08 \mathrm{C} 0.5 \mathrm{Fe} 2.0 \mathrm{Mo}$. Accordingly, these alloys exhibit a higher degree of recrystallization. Nevertheless, residual grain boundary- $\alpha$ is still visible. This as well as the residual lamellar structures shows that the degree of deformation during rotary swaging was not high enough to break the laths completely. Furthermore, the repeated annealing between each pass during rotary swaging could have led to recovery of the microstructure, which - as a result limits the degree of recrystallization. Therefore, a complete recrystallization of the samples could not be reached in laboratory conditions.
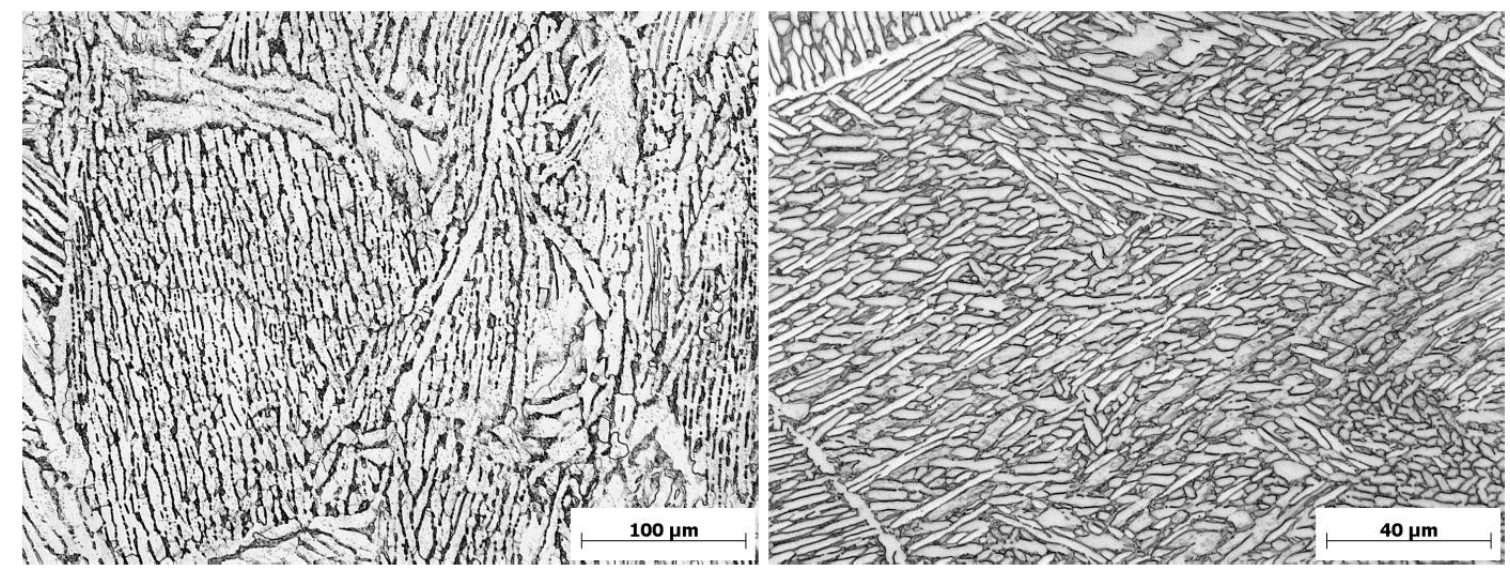

Figure 1: Microstructure of Ti 0.42O 0.08C 0.5Fe 0.4Si (left) and of Ti 0.44O 0.08C 0.5Fe 2.0Mo (right) after recrystallization (longitudinal direction)

The microstructure of $\mathrm{Ti} 0.4 \mathrm{O} \quad 0.5 \mathrm{Fe} \quad 0.08 \mathrm{C} \quad 0.3 \mathrm{Si} 0.1 \mathrm{Au}$ (produced in larger quantities) after rotary swaging and recrystallization consists of globular $\alpha_{\mathrm{p}}$-grains. Local EDS analysis shows an Fe-enrichment in grains alongside of $\alpha$-grains, indicating the presence of a small amount of $ß$-phase.

Figure 2, left, shows the microstructure of Ti $0.44 \mathrm{O} 0.5 \mathrm{Fe} 0.08 \mathrm{C} 0.4 \mathrm{Si} 0.1 \mathrm{Au}$ along the longitudinal direction (differential interference contrast, DIC) after a recrystallization treatment at $800^{\circ} \mathrm{C}$ for $2 \mathrm{~h}$ with subsequent air cooling. It can be seen that this heat treatment led to a fine recrystallized, globular microstructure with an average grain size of approx. $11 \mu \mathrm{m}$. Nevertheless, some residual lamellar structures are still present as well as larger $\alpha_{\mathrm{p}}$-grains along prior $\beta$-grain boundaries. Generally, the $\beta$-grains have a size of a few micrometers. Although the recrystallization temperature is low with respect to $\beta-$ transus $\left(1000^{\circ} \mathrm{C}-1025^{\circ} \mathrm{C}\right)$, the overall amount of $\beta$-phase in the alloy is quite high, as can be seen in Figure 3 , which shows a SEM-image (BSE) of the microstructure in longitudinal direction together with the corresponding distribution of the alloying element Fe according to EDS analysis. The enrichment of Fe in grains alongside of $\alpha_{\mathrm{p}}$-grains clearly indicates the presence of B-phase in the alloy. Figure 2, right, shows the diffraction pattern of the alloy (smoothed) after a recrystallization treatment at $800^{\circ} \mathrm{C}$ for $1 \mathrm{~h}$ with subsequent air cooling. The corresponding microstructure of the sample is almost identical to the microstructure shown in this figure. As can be seen, only peaks of the $\alpha$ - and $\beta$-phase are present. One peak, however, could not be attributed to either $\alpha$ - or $\beta$-phase or to $\mathrm{Ti}_{5} \mathrm{Si}_{3}$, TiC, or FeTi. The latter might form according to Thermo-Calc ${ }^{\circledR}$ simulations.
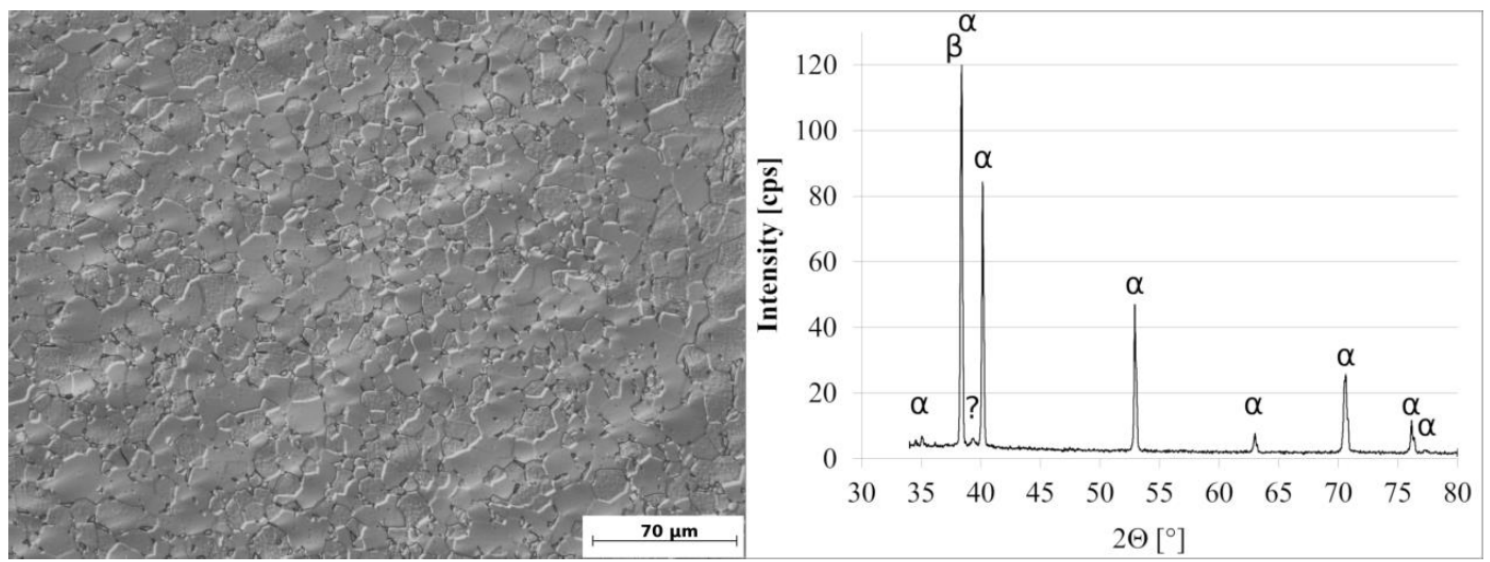
Figure 2: Left: Globular microstructure (DIC-contrast) of Ti 0.44O 0.5Fe 0.08C 0.4Si 0.1Au (produced in larger quantities) in longitudinal direction after recrystallization $\left(800^{\circ} \mathrm{C} / 2 \mathrm{~h} / \mathrm{AC}\right)$; Right: Diffraction pattern (smoothed) of the same alloy after recrystallization $\left(800^{\circ} \mathrm{C} / 1 \mathrm{~h} / \mathrm{AC}\right)$

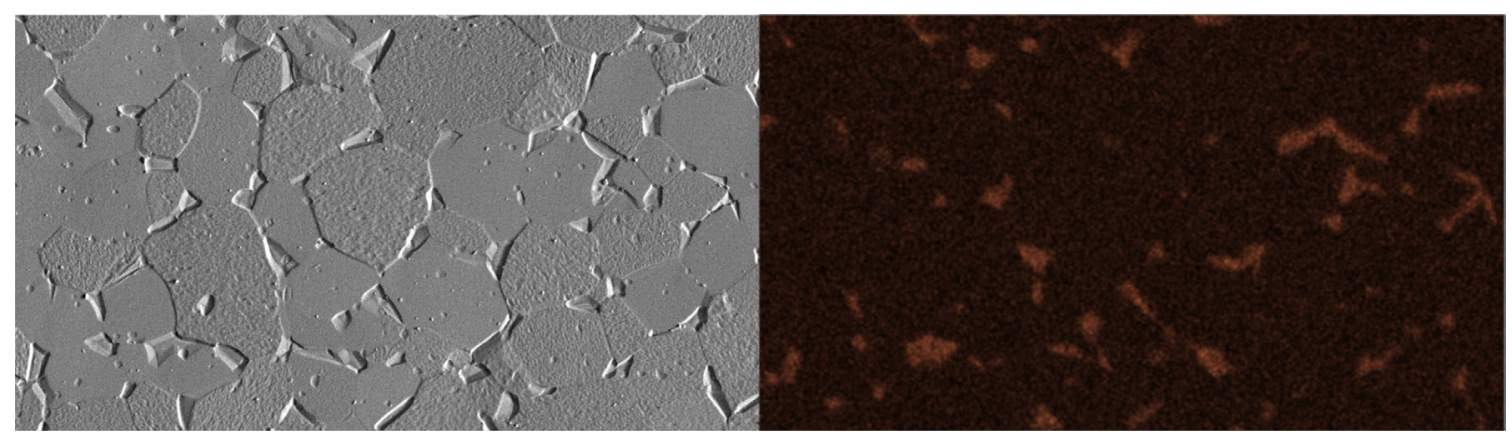

Figure 3: Left: SEM-image (BSE) of Ti 0.440 0.5Fe 0.08C 0.4Si 0.1Au in longitudinal direction after recrystallization treatment $\left(8^{\circ}{ }^{\circ} \mathrm{C} / 2 \mathrm{~h} / \mathrm{AC}\right)$; Right: Corresponding distribution of Fe according to EDS analysis

Mechanical properties

Table 2 summarizes the mechanical properties of the studied alloys. Additionally, properties of $\mathrm{Ti} 0.4 \mathrm{O} 0.08 \mathrm{C} 0.5 \mathrm{Fe}(\mathrm{CP}-\mathrm{Ti}$ Grade $4^{+}$), CP-Ti Grade 4, and Ti 6Al 4V ELI, taken from [9], are listed for comparison.

Table 2: Mechanical properties of the studied alloys and comparison with selected titanium alloys

\begin{tabular}{lcccc} 
Alloy & Hardness [HV10] & YTS [MPa] & UTS [MPa] & A [\%] \\
\hline Ti 0.42O 0.08C 0.5Fe 0.4Si & $311^{1)}$ & $971^{1)}$ & $983^{1)}$ & $16^{1)}$ \\
Ti 0.440 0.08C 0.5Fe 0.4Si & $313^{1)}$ & $987^{1)}$ & $993^{1)}$ & $15^{1)}$ \\
\hline \hline Ti 0.40O 0.08C 0.5Fe 2.0Mo & $309^{1)}$ & $979^{1)}$ & $991^{1)}$ & $16^{1)}$ \\
\hline Ti 0.440 0.08C 0.5Fe 2.0Mo & $315^{1)}$ & $1006^{1)}$ & $1016^{1)}$ & $17^{1,2)}$ \\
\hline \hline Ti 0.40O 0.08C 0.5Fe 2.0Nb & $300^{1)}$ & $900^{1)}$ & $903^{1)}$ & $18^{1)}$ \\
\hline Ti 0.440 0.08C 0.5Fe 2.0Nb & $306^{1)}$ & $929^{1)}$ & $932^{1)}$ & $18^{1)}$ \\
\hline \hline Ti 0.40O 0.08C 0.5Fe 0.3Si 0.1Au & $274^{3)}$ & $778^{3)}$ & $846^{3)}$ & $22^{3)}$ \\
\hline Ti 0.44O 0.08C 0.5Fe 0.4Si 0.1Au & $334^{4)}$ & & Not yet investigated & \\
\hline \hline Ti 0.4O 0.08C 0.5Fe & $275^{5)}$ & $690^{5)}$ & $730^{5)}$ & $20^{5)}$ \\
\hline CP-Ti Grade 4 & $220^{5)}$ & $530^{5)}$ & $620^{5)}$ & $19^{5)}$ \\
\hline Ti 6Al 4V ELI & & $483^{6)}$ & $550^{6)}$ & $15^{6)}$ \\
\hline
\end{tabular}

1) Laboratory-size specimens, rotary swaged and recrystallized

2) Minimum ductility, since one specimen failed outside of the tolerated section according to DIN EN ISO 6892-1

${ }^{3)}$ Material produced in larger quantities, rotary swaged and recrystallized

4) Material produced in larger quantities, rolled and recrystallized

${ }^{5)}$ Laboratory-size specimens, rotary swaged and recrystallized; taken from [9]

6) Minimum requirements according to ASTM F67

7) Minimum requirements according to ASTM F136

In terms of the alloys which have been produced in laboratory conditions, it can be seen that all of them exhibit a higher YTS and UTS than Ti $0.4 \mathrm{O} 0.08 \mathrm{C}$ 0.5Fe and CP-Ti Grade 4 (both alloys produced in laboratory conditions) in combination with a ductility of more than $10 \%$ (minimum ductility of Ti $6 \mathrm{Al} 4 \mathrm{~V}$ ELI according to ASTM F136). Moreover, they all meet the requirements of Ti 6Al 4V ELI according to ASTM F136. However, in terms of UTS and ductility, not all alloys actually show better mechanical properties than $\mathrm{Ti} 6 \mathrm{Al} 4 \mathrm{~V}$ ELI which has been produced in laboratory conditions. Ti $0.44 \mathrm{O} 0.08 \mathrm{C}$ 
0.5Fe 2.0Mo exhibits the highest YTS and UTS of $1006 \mathrm{MPa}$ and $1016 \mathrm{MPa}$, respectively. In contrast to that, both $\mathrm{Nb}$ containing alloys have the lowest static strengths.

These results confirm the expectations, since Mo is a stronger $\beta$-stabilizer than $\mathrm{Nb}$ [1], whereby the Mo-containing alloys exhibit a higher amount of $\beta$-phase, which leads to more phase boundaries, to a better recrystallization and, as a consequence, to better mechanical properties. Si decreases $\beta$-transus only slightly [11], but the difference in atomic radius compared to $\mathrm{Ti}$ is high, so that $\mathrm{Si}$ is a potent solution strengthener. $\mathrm{O}$ also significantly distorts the lattice [1], so that even small increases in O-content from $0.40 / 0.42 \%$ to $0.44 \%$ lead to a significant increase in YTS and UTS.

Assessment of the fracture surface of the tensile specimens of the alloys which have been produced in laboratory conditions (see Figure 4, which shows exemplarily the fracture surface of Ti $0.42 \mathrm{O} 0.08 \mathrm{C} 0.5 \mathrm{Fe} 0.4 \mathrm{Si}$ ) revealed mostly dimples and therefore a microscopic ductile fracture [12]. However, local cleavage fractures are present, see Figure 4, right.
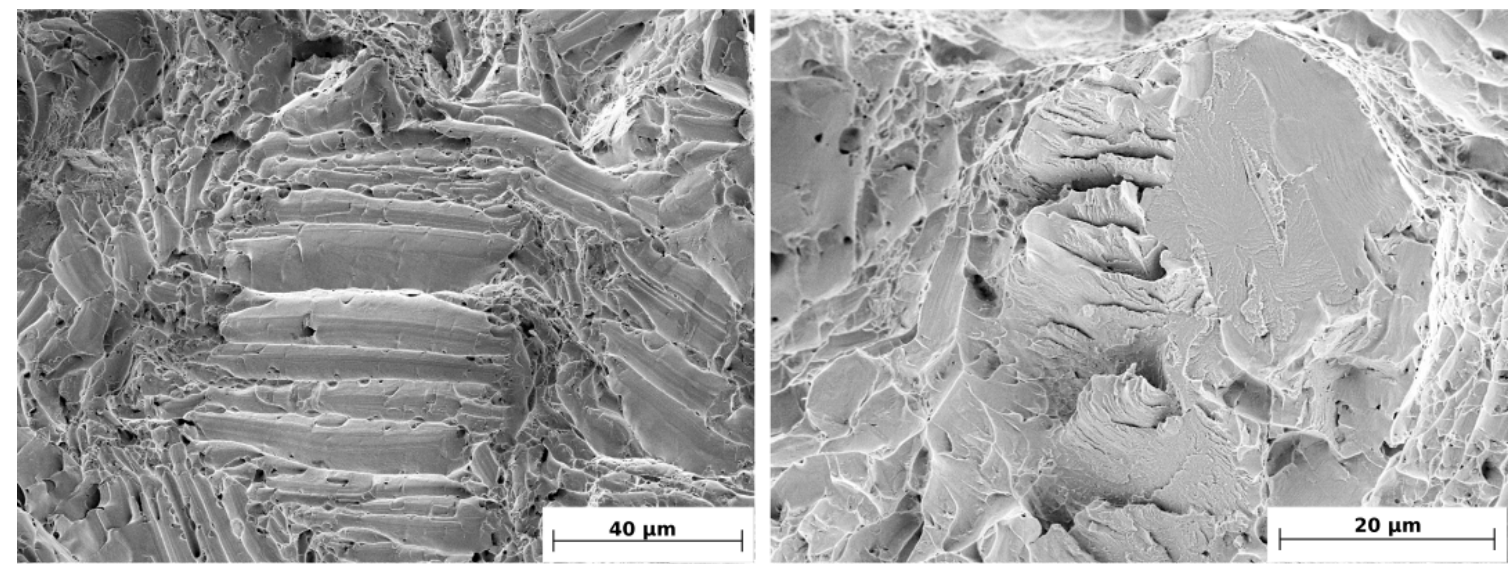

Figure 4: Left: Dimples on the fracture surface of Ti 0.42O 0.08C 0.5Fe 0.4Si; Right: Local cleavage fractures of the same alloy

Nevertheless, despite the good mechanical properties of the laboratory-size specimens, it has to be noted that all of them exhibit a high strength ratio. This might be due to the incomplete recrystallization of the specimens as a result of the limited degree of deformation and the potential recovery of the microstructure during rotary swaging, which - as already mentioned - results in a mainly lamellar microstructure.

Ti $0.40 \mathrm{O} 0.08 \mathrm{C} 0.5 \mathrm{Fe} 0.3 \mathrm{Si} 0.1 \mathrm{Au}$, which has been produced in larger quantities, exhibits a YTS and UTS of $778 \mathrm{MPa}$ and $846 \mathrm{MPa}$, respectively, in combination with a ductility of $22 \%$ in rotary swaged and recrystallized state. Therefore, it does not meet the requirements of Ti 6Al 4V ELI according to ASTM F136. Nevertheless, the mechanical properties are much better compared to $\mathrm{CP}$-Ti Grade 4 and Ti $0.4 \mathrm{O} 0.08 \mathrm{C} 0.5 \mathrm{Fe}$ (both produced in laboratory-conditions). Moreover, the alloy exhibits an endurance limit of $555 \mathrm{MPa}$, which is $71 \%$ of the measured yield strength.

Ti $0.44 \mathrm{O} 0.08 \mathrm{C} 0.5 \mathrm{Fe} 0.4 \mathrm{Si} 0.1 \mathrm{Au}$, also produced in larger quantities, shows a hardness of $334 \mathrm{HV} 10$ (rolled and recrystallized) and, therefore, the highest hardness of all mentioned alloys. Tensile tests of this alloy are in preparation at present.

\section{Conclusion}

In the present study, several alloys on the basis of CP-Ti Grade $4^{+}(\mathrm{Ti} 0.4 \mathrm{O} 0.5 \mathrm{Fe} 0.08 \mathrm{C})$ for implant and osteosynthesis applications have been studied, which contain $\mathrm{O}, \mathrm{C}, \mathrm{Fe}, \mathrm{Au}, \mathrm{Si}, \mathrm{Nb}$ or Mo as alloying elements. Tensile tests show that all alloys which have been produced in laboratory conditions exhibit a higher YTS, UTS, and elongation at fracture than the minimum requirements of Ti $6 \mathrm{Al} 4 \mathrm{~V}$ ELI according to ASTM F136. Although this is not the case for Ti $0.40 \mathrm{O} 0.08 \mathrm{C} 0.5 \mathrm{Fe}$ $0.3 \mathrm{Si} 0.1 \mathrm{Au}$ (produced in larger scales), the alloy exhibits a much higher YTS and UTS than CP-Ti Grade 4 (produced in laboratory conditions) in combination with an endurance limit of $555 \mathrm{MPa}(71 \%$ of the measured YTS). As a conclusion, some of the studied alloys might be a promising replacement for Ti 6Al 4V ELI in osteosynthesis and implant applications, since they combine good mechanical properties and a better corrosion resistance with a supposed higher biocompatibility due to the exclusion of $\mathrm{Al}$ and $\mathrm{V}$.

\section{Acknowledgements}

This study was financially supported by the AiF Arbeitsgemeinschaft industrieller Forschungsvereinigungen "Otto von Guericke" e.V., project IGF 19708 N, which is greatly acknowledged. Furthermore, the authors would like to thank S. Voigt 
and T. Sahin from VACUCAST in Berlin, Germany, for the production of Ti $0.44 \mathrm{O} 0.5 \mathrm{Fe} 0.08 \mathrm{C} 0.4 \mathrm{Si} 0.1 \mathrm{Au}$ in larger quantities.

\section{References}

[1] G. Lütjering, J. C. Williams: Titanium, 2nd Ed., Springer, Berlin (2007)

[2] M. Geetha, A. K. Singh, R. Asokamani, A. K. Gogia: Ti based biomaterials, the ultimate choice for orthopaedic implants - A review, Progress in Materials Science 54 (2009), No. 3, pp. 397 - 425

[3] Y. Li, C. Yang, H. Zhao, S. Qu, X. Li, Y. Li: New developments of ti-based alloys for biomedical applications, Materials 7 (2014), No. 3, pp. $1709-1800$

[4] A. Langley, C. T. Dameron: Modern metal implant toxicity and anaesthesia, R. Riley (Ed.): Australasian anaesthesia 2015: Invited papers and selected continuing education lectures, Australian and New Zealand College of Anaesthetists, Melbourne Victoria, Australia (2015), pp. $57-65$

[5] C. N. Elias, J. H. C. Lima, R. Valiev, M. A. Meyers: Biomedical applications of titanium and its alloys, JOM 60 (2008), No. 3, pp. $46-49$

[6] S. J. Mandriota, M. Tenan, P. Ferrari, A. Sappino: Aluminium chloride promotes tumorigenesis and metastasis in normal murine mammary gland epithelial cells, International Journal of Cancer 139 (2016), No. 12, pp. 2781 - 2790

[7] C. Siemers, D. Wolter, H. Sibum: New, aluminum- and vandium-free titanium alloys for osteosynthesis applications, V. Venkatesh, A. L. Pilchak, J. E. Allison, S. Ankem, R. Boyer, J. Christodoulou, H. L. Fraser, M. A. Imam,

Y. Kosaka, H. J. Rack, A. Chatterjee, A. Woodfield (Eds.): Proceedings of the 13th world conference on titanium, John Wiley \& Sons, Inc, Hoboken, NJ, USA (2016), pp. $1665-1668$

[8] D. R. Williams: Metals, ligands, and cancer, Chemical Reviews 72 (1972), No. 3, pp. 203 - 213

[9] C. Siemers, F. Brunke, K. Saksl, J. Kiese, M. Kohnke, F. Haase, M. Schlemminger, P. Eschenbacher, J. Fürste, D. Wolter, H. Sibum: Development of advanced titanium alloys for aerospace, medical and automotive applications: Proceedings of the xxviii international mineral processing congress, september 11-15, québec city, canada, Canadian Institute for Mining, Metallurgy \& Petroleum (2016), pp. 3600 - 3611

[10] B. H. Toby: CMPR - a powder diffraction toolkit, Journal of Applied Crystallography 38 (2005), No. 6, pp. 1040 1041

[11] T. B. Massalski (Ed.): Binary alloy phase diagrams, American Society for Metals, Metals Park, Ohio (1986)

[12] G. Lange: Mikroskopische und makroskopische Erscheinungsformen des duktilen Gewaltbruches (Gleitbruch), G. Lange, M. Pohl (Eds.): Systematische Beurteilung technischer Schadensfälle, 6th Ed., Wiley-VCH, Weinheim, Germany (2014), pp. $79-102$ 